\title{
A incapacidade de reparação integral de danos ambi- entais às comunidades tradicionais no sistema jurídico monista e sua realidade na América Latina
}

Inability to repair of comprehensive environmental damage to traditional communities in your reality and monistic legal system in Latin America

\section{Fernando Murilo Costa Garcia ${ }^{[a],}$ Leonardo Tossulino $^{[\mathrm{b}]}$}

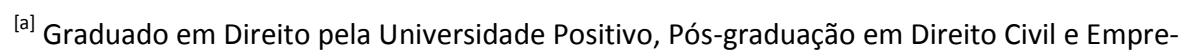
sarial pela PUC-PR, Mestrando em Direito Econômico e Socioambiental pela PUC-PR; é sócio fundador do escritório Neves Macieywski, Garcia \& Advogados Associados. Curitiba, PR-Brasil, e-mail: fernando@nm.adv.br

${ }^{[b]}$ Graduando em Direito pela Pontifícia Universidade Católica do Paraná; é Assistente Jurídico no escritório Neves Macieywski, Garcia \& Advogados Associados. Curitiba, PR-Brasil, email: leotossulino@gmail.com

\section{Resumo}

Com advento da sociedade de risco e da crescente evolução da fronteira agrícola, novos confrontos sociais passam a se destacar: De um lado, o crescente discurso que impõem uma necessidade de desenvolvimento econômico, e de outro, comunidades tradicionais, povos que possuem seu modo de ser e viver atrelados ao meio ambiente em que convivem, e que dificilmente sobrevivem em outras circunstâncias. Porém a realidade e as necessidades 
destes povos distanciam-se da realidade conhecida, e enfrentada diariamente, pelo Poder Judiciário demonstrando que o atual sistema não se encontra capacitado para uma solução satisfatória destes conflitos, colocando em perigo o meio ambiente e a sobrevivência destas comunidades. A partir destes conflitos apresentam-se a análises da presente estudo que busca dar uma nova ótica através do pluralismo jurídico como solução mais eficaz, na reparação do dano ambiental às comunidades tradicionais, atendendo as necessidade destas comunidades e a realidade da América Latina.

Palavras-chave: Comunidades tradicionais. Dano ambiental. Reparação integral.

\section{Abstract}

With the advent of risk society and the increasing evolution of the agricultural frontier, new social conflicts come to the fore: On one hand, the growing discourse that imposes a need for economic development and other, traditional communities, people who own their mode living and being tied to the environment in which they live, and unlikely to survive in other circumstances. But the reality and needs of these people distance themselves from known reality, and faced daily by the judiciary demonstrating that the current system is not able to satisfactorily resolve these conflicts, endangering the environment and the survival of these communities. From these conflicts are presented the analyzes of this study, which seeks to give a new perspective through the legal pluralism as a more effective solution to repair the environmental damage to traditional communities, meeting the needs of these communities and the reality of Latin America.

Keywords: Traditional communities. Environmental damage. Full compensation.

\section{Introdução}

$\mathrm{Na}$ atualidade as mais diversas situações são levadas ao Poder Judiciário a fim de buscar uma solução, e em muitos casos, uma reparação. Todavia diferentemente dos casos clássicos de acidentes de trânsito e de inadimplementos contratuais, o sistema monista utilizado pelo judiciário que, adotou a reparação pecuniária como sua melhor prestação jurisdicional, falia ao ser provocado por comunidades que sobrevivem em uma relação íntima com a natureza e completamente apáticas ao ideal capitalista.

Neste contexto reside o escopo da presente análise que busca demonstrar a falia do sistema monista no que concerne a reparação de 
danos ambientais a comunidades que possuem seu modo de vida harmonicamente atrelada ao meio ambiente em que vivem.

\section{A incapacidade de reparação integral de danos ambientais às comunidades tradicionais}

Dado o avanço da fronteira agrícola, o advento da sociedade de risco ${ }^{1}$ e a intensificação da superprodução desenfreada em nosso país e no mundo, novos paradigmas desta equação se somam aos demais problemas da sociedade hodierna.

No Brasil, a fronteira agrícola alcançou as comunidades tradicionais, trazendo problemas e até confrontos sociais, dividindo e colocando de um lado o discurso da necessidade de desenvolvimento econômico e de outro, povos que possuem seu modo de ser e viver completamente atrelados ao meio ambiente em que convivem, o oposto da civilização urbanizada.

Em conjunto ao meio ambiente esta comunidades mantém o seu modo de ser e viver, sempre de uma maneira bastante afastada da superprodução global, ou mesmo de um meio industrial, pelo contrário, geralmente praticando agricultura ou cultivo de subsistência, extrativismo e caça.

O próprio modo de ser e viver destas comunidades possui um baixíssimo impacto ambiental (para não dizer nenhum), numa convivência harmoniosa em um mutualismo completamente dependente.

Estas comunidades possuem uma conexão tão grande com o meio ambiente em que vivem, que dificilmente sobreviveriam em outras con-

\footnotetext{
“A revolução industrial do século XVIII foi o embrião do que se chama hoje de sociedade de risco, potencializada pelo desenvolvimento tecnocientífico e caracterizada pelo incremento na incerteza quanto às consequências das atividades e tecnologias empregadas no processo econômico).

Notadamente, a sociedade pós-moderna produz riscos que podem ser controlados e outros que escapam ou neutralizam os mecanismos de controle típicos da sociedade industrial. A sociedade de risco revela-se, portanto, um modelo teórico que marca a falência da modernidade, emergindo de um período pós moderno, à medida que as ameaças produzidas ao longo da sociedade industrial começam a tomar forma. Os pilares da concepção moderna de civilização já não conseguem mais explicar os desenvolvimentos da ciência e da sociedade. Trata-se de uma crise de paradigma, uma crise própria da modernidade. Referida crise torna praticamente inviável, pelo menos nos moldes clássicos, qualquer tentativa do homem pós-moderno no sentido de calcular os riscos e os desafios a que se submete o meio ambiente no século XXI." (LEITE, 2012, p. 14.)
} 
dições, ou mesmo em ambientes diferente daquele em que estão inseridos.

As peculiaridades não são apenas estas, as comunidades tradicionais possuem culturalmente uma comunicação própria com seus membros e com a natureza através de um equilíbrio que dá origem a seus costumes, a sua religião e a sua cultura cunhando uma identidade própria da comunidade, sempre intimamente conectado com o meio em que vivem.

Dentro desta perspectiva, os valores destes povos são completamente diferentes dos valores da sociedade em geral, que vivem num meio urbano, de cultura e de vida atrelados ao indivíduo e ao modo de vida produzido pelo capitalismo moderno, e é neste indivíduo que todo o sistema que governa o país (político, social, econômico e judicial) está embasado.

Ocorre, que este sistema não foi criado, ou melhor preparado, para a resolução de conflitos entre povos tradicionais (coletivo) e o indivíduo inserido nesta sociedade individualista, ou mesmo as empresas por estes constituídas.

Assim, por estar o sistema atual preparado tão somente para os conflitos e problemas existentes entre a maioria, e não com as comunidades tradicionais, há uma séria falha para a qual, principalmente o Poder Judiciário, como última instância, não se demonstra capacitado para uma solução satisfatória de ambos os lados.

Os danos ambientais produzidos pela sociedade de risco, principalmente na busca do chamado desenvolvimento econômico, colocam em perigo o meio ambiente e a sobrevivência de toda sociedade, mas quando atingem comunidades tradicionais os impactos são mais gravosos, face a dependência destes povos com o ambiente em que vivem.

É na busca de soluções, que a própria lei preconiza, de casos onde o dano ambiental produzido pela sociedade atinge o meio ambiente de uma comunidade tradicional que o sistema se apresenta ineficaz, visto que danos ao ambiente destas comunidades colocam facilmente em risco a vida de todos que constituem essas comunidades. 


\section{O dano ambiental e o princípio da reparação integral na legis- lação brasileira}

A proteção jurídica do bem ambiental em nosso ordenamento pátrio jurídico não se importa com o patrimônio do ofendido, mas com o bem em si, tal como pode verificar-se no seguinte exemplo didático:

Se houve uma deterioração em um prédio histórico, por exemplo, evidentemente houve uma perda para o patrimônio histórico da cidade ou do país, mas não é essa perda que ganha relevância jurídica, e sim a violação da norma protetora, o que interessa é o dano causado ao bem. Isto se dá igualmente com o patrimônio natural, porque se há a derrubada de uma árvore imune de corte, não importa o patrimônio do proprietário da árvore, mas sim a violação da proteção em si mesmo porque a derrubada da árvore imune de corte pode até aumentar o patrimônio do titular, que poderá vender a madeira ou ter o seu terreno valorizado comercialmente. [...] É que o patrimônio socioambiental não se valora economicamente, mas é apenas o conjunto de bens existentes, por isso cada um deles é tratado como se fosse o único. (MARÉS, 2002, p. 43)

Tal tratamento estende-se a responsabilização pelo dano ambiental que através da Teoria do Risco Integral adotou a responsabilidade objetiva o qual possui menção expressa na Constituição Federal brasileira no art. 225, $3^{\circ}$ e no art. $14, \S 1^{\text {o }}$ da Política Nacional do Meio Ambiente (lei n. 6.938/81), fazendo-se necessária, para a responsabilização pelo evento danoso, somente a constatação do nexo de causalidade entre o dano de natureza ambiental e a conduta do agente independentemente de culpa.

Nas palavras de Morato Leite (2012, p.27) trata-se "sem dúvida, de um avanço normativo, vez que a não necessidade de comprovação da culpa do agente degradador, por conta do risco da atividade exercida, facilita, pelo menos em tese, a responsabilização".

O legislador brasileiro classificou a responsabilidade civil ambiental como objetiva, independente de culpa, colocando o poluidor em posição de responsabilidade mesmo em caso de ausência de culpa dada a máxima proteção bem, consagrado pela Constituição Federal.

Adotando a responsabilidade objetiva, o legislador supriu a dificuldade de determinação do causador do dano ambiental, uma vez que a 
determinação em muitos casos pode impossibilitar a própria reparação do dano, motivo pelo qual optou-se pela responsabilidade objetiva.

Neste sentido, inclusive o Superior Tribunal de Justiça, ao julgar o recurso especial n. 1.114.398/PR ${ }^{2}$ em sede de recurso repetitivo, definiu jurisprudencialmente a aplicação da responsabilidade objetiva do poluidor em casos de dano ambiental, não admitindo inclusive excludentes de responsabilidade.

Quanto a reparação do dano ambiental, verifica-se que esta deve observar com rigor o retorno ao status in natura ou quo ante, ou seja, o estado anterior ao evento danoso com respaldo ao Princípio da Reparação Integral.

Este princípio adotado pela legislação brasileira entende que em se tratando de dano ambiental o bem atingido, a vítima lesada e ecossistema degradado devem ser reparados integralmente tendo como objetivo o retorno ao estado anterior ao dano, ou ainda, nas palavras de Milaré (2005, p. 830) significa dizer "que a lesão causada ao meio ambiente há de ser recuperada em sua integridade" o autor ainda adverte que "qualquer norma jurídica que disponha em sentido contrário ou que pretenda limitar o montante indenizatório a um teto máximo deva ser considerada inconstitucional" tamanho rigor atribuído ao trato com o dano ao meio ambiente.

Todavia se aquele que aufere lucro com determinada atividade (sic. LIPARI, 1978, p. 64.) causar danos ao meio ambiente (poluidor), diante da inviabilidade da reparação do local afetado, oportuniza-se ao

\footnotetext{
AÇÃO DE INDENIZAÇÃO - DANOS MATERIAIS E MORAIS A PESCADORES CAUSADOS POR POLUIÇÃO AMBIENTAL POR VAZAMENTO DE NAFTA, EM DECORRÊNCIA DE COLISÃO DO NAVIO N-T NORMA NO PORTO DE PARANAGUÁ - 1) PROCESSOS DIVERSOS DECORRENTES DO MESMO FATO, POSSIBILIDADE DE TRATAMENTO COMO RECURSO REPETITIVO DE TEMAS DESTACADOS PELO PRESIDENTE DO TRIBUNAL, À CONVENIÊNCIA DE FORNECIMENTO DE ORIENTAÇÃO JURISPRUDENCIAL UNIFORME SOBRE CONSEQUÊNCIAS JURÍDICAS DO FATO, QUANTO A MATÉRIAS REPETITIVAS; 2) TEMAS: a) CERCEAMENTO DE DEFESA INEXISTENTE NO JULGAMENTO ANTECIPADO, ANTE OS ELEMENTOS DOCUMENTAIS SUFICIENTES; b) LEGITIMIDADE DE PARTE DA PROPRIETÁRIA DO NAVIO TRANSPORTADOR DE CARGA PERIGOSA, DEVIDO A RESPONSABILIDADE OBJETIVA. PRINCÍPIO DO POLUIDOR-PAGADOR; c) INADMISSÍVEL A EXCLUSÃO DE RESPONSABILIDADE POR FATO DE TERCEIRO; d) DANOS MORAL E MATERIAL CARACTERIZADOS; e) JUROS MORATÓRIOS: INCIDÊNCIA A PARTIR DA DATA DO EVENTO DANOSO - SÚMULA 54/STJ; f) SUCUMBÊNCIA. 3) IMPROVIMENTO DO RECURSO, COM OBSERVAÇÃO. STJ. Rel. Min. Sidnei Beneti. DJe. 16/02/2012.
} 
agente causador do dano uma forma indireta de sanar o dano: a indenização pecuniária ou reparação econômica.

Ocorre que em alguns casos a indenização pecuniária não é a mais adequada, sendo oportunizada tão somente ante a inviabilidade da reparação do local, não atendendo aos reais anseios dos lesados.

Tal como é o caso das comunidades tradicionais pois nestas, mais que em qualquer outra situação, um dano ao meio ambiente assume a qualidade de dano socioambiental, uma vez que o referido dano infligirá sobre a comunidade, tratando-se de danos que ultrapassarão a esfera do meio ambiente, atingindo inclusive suas vidas cotidianas, seu modo de ser e viver, seu patrimônio cultural.

\section{As particularidades das comunidades tradicionais: um bem jurid- icamente desprotegido}

Em 07 de fevereiro de 2007, foi exarado o decreto $n^{\circ}$. 6.040, que veio a instaurar a Política Nacional de Desenvolvimento Sustentável dos Povos e Comunidades Tradicionais.

Esta PNPCT garantiu de maneira expressa os direitos sociais, territoriais, econômicos, culturais e ambientais às comunidades tradicionais, positivando ainda o atual conceito de comunidades tradicionais, que nada mais são que:

\footnotetext{
Grupos culturalmente diferenciados e que se reconhecem como tais, possuidores de formas próprias de organização social, ocupantes e usuários de territórios e recursos naturais como condição à sua reprodução cultural, social, religiosa, ancestral e econômica, utilizando conhecimentos, inovações e práticas gerados e transmitidos pela tradição.
}

Os valores das comunidades tradicionais obviamente são peculiares à cada uma destas comunidades, podendo haver semelhanças. 0 que se pode dizer é que os valores destas estão bem distantes dos valores da sociedade, para os quais a lei e o judiciário foram criados.

Isto tanto é verdade que todo o sistema legislativo é baseado em relações individuais, relações contratuais, para Marés (in OLIVEIRA, 1999, p. 309.) a organização estatal foi criada unicamente para garantir, individualmente, o exercício de direitos e não está apta para atender as 
necessidades de relações coletivas, como é o caso das comunidades tradicionais, temos aqui a origem do problema a que nos referimos.

É de se notar que este pressuposto acaba por macular toda a legislação, uma vez que, por mais que o legislativo se esforce em proteger direitos de minorias como os povos tradicionais, isso não ocorre de maneira satisfatória, porque sempre o faz através do direito sob o prisma individual, do direito e da racionalidade europeia.

Neste mesmo sentido adverte a doutrina:

Assim tem sido as reivindicações por direitos coletivos no Estado Moderno. Nenhum poder deve existir entre o Estado e o cidadão, proclamava a Revolução Francesa. Ou o poder era do Estado, que garantia a realização dos direitos individuais, ou o poder era do indivíduo que, garantido pelo Estado, exercia seus direitos individuais. Qualquer ser impessoal que se estabelecesse como intermediário, rompia a dicotomia, quebrava a unidade e, consequentemente, a lógica do sistema.

Por isso mesmo os direitos coletivos são invisíveis ainda hoje. Cada vez que são propostos ou reivindicados, é desqualificado o seu sujeito: o povo indígena, se reivindica um direito coletivo, deve fazê-lo como pessoa jurídica, o MST só pode ser visto como reivindicante de direitos individuais à propriedades de lotes de terra. Exatamente por isso a extrema dificuldade do Poder Judiciário em entender ou acatar o direito coletivo reivindicado e, invariavelmente, conceder liminares para desocupações coletivas de terra garantindo o direito individual do proprietário. (MARÉS in OLIVEIRA, 1999, p. 313)

Os valores das comunidades tradicionais e sua própria identidade se encontram em sua coletividade e não no indivíduo, por isso também a dificuldade deste direito tão enraizado na lógica racional individualista de compor os problemas destas comunidades.

Também deve-se salientar, que os valores das comunidades em sua grande maioria não estão interligados aos bens econômicos como conhecemos. Neste sentido, o seu modo de ser e viver depende do meio ambiente em que convive e é à ele que seus valores e respeito se resguardam. 
De maneira bastante expressa, os valores destas comunidades muitas vezes não se representam em capital, pelo contrário é justamente o capital que não possui qualquer valor para estas comunidades.

\section{Da incapacidade de avaliação de reparação integral face as co- munidades tradicionais no sistema monista}

O sistema de responsabilidade civil brasileiro, inclusive na reparação dos danos ambientais, coloca-se sempre como um sistema de perdas e danos, buscando devolver a vítima seu status quo ante pela via econômica mesmo que o dano não possua esta mesma natureza.

0 próprio dano ambiental possui sua reparação determinada legislativamente para que busque-se a reconstituição do ambiente atingido, não obstante, na maioria dos casos isso não acontecer por simples impossibilidade pratica.

Assim, não escapa aos olhos da lei que o infrator, neste caso poluidor, possui o dever de reparar o dano, sobre caindo ao valor econômico estabelecido através de um juízo de valores, geralmente exercido pelo Poder Judiciário ou pela Administração Pública a recomposição pecuniária do bem.

Todavia, como supra descrito a indenização (via pecúnia) está em segundo plano, de modo que caso torne-se impossível a recomposição do bem, é que passa-se a avaliar o dano a fim de que seja estabelecido um parâmetro pecuniário para indenização pelo dano.

Além do mais a recomposição ou indenização deve ser integral, advertindo LEITE (2012, p. 132) que por tratar-se de um dano multifacetado, existam diversas variantes que devem compor uma indenização pelo dano ambiental.

Questiona-se o que fazer quando o dano ambiental atingir uma ou várias comunidades tradicionais? Qual é a seria a melhor forma de reparação? Quem analisaria o melhor meio de recomposição?

Primeiramente deve ser levado em consideração o valor da ou das comunidades tradicionais vitimadas pelo dano, pois para algumas comunidades uma indenização em pecúnia pode até representar alguma coisa, porém certamente está não será a melhor forma de indenizar um dano ambiental.

Deve-se notar que um dano ambiental à uma comunidade tradicional toma proporções muito mais graves, haja vista seu modo de ser e 
viver completamente dependente ao ecossistema em que a comunidade se encontra inserida.

Em análise o próprio dano não pode ser analisado de maneira individual, como preconiza a lei, pois nestes casos o dano não é coletivo simplesmente porque o bem atingido é difuso, mas porque a identidade dos indivíduos da comunidade e seus valores estão atrelados ao povo como unidade coletiva, e não ao indivíduo.

Resta patente a dificuldade de se resolver conflitos em que os valores econômicos são diferentes, a concepção de meio de vida e de convivência social são completamente diferentes daqueles encontrados nos cadernos jurídicos, nas jurisprudências comuns e no dia-a-dia dos Tribunais.

Salienta-se que o próprio sistema jurídico, consolidado no Estado como único Poder e fonte das Leis, acaba por colmatar este sistema que não possui visão holística das diversas culturas hoje envolvidas.

Este sistema denominado de "monismo jurídico" consolidado ao longo da modernidade, segundo Carvalho (In WOLKMER, 2010, p. 14) caracteriza-se pelo fato do Estado ser o centro do sistema por ser o único detentor do poder de produção das normas jurídicas (direitos e deveres), de modo que a lei torna-se válida pelo simples fato de ser lei, e sua legitimidade advém da mera observância aos procedimentos previamente estabelecidos, isto é, das normas que regulam o processo legislativo.

Desta maneira, o direito se coloca como instrumento apenas para uma sociedade hegemônica ${ }^{3}$ e não para as minorias, de tal forma que as minorias acabam por ser excluídas do contexto.

Como os Magistrados, os Promotores, e até mesmo Procuradores de classes podem avaliar o que é necessário e melhor para estes povos que possuem seu modo de ser e viver completamente diferente dos

\footnotetext{
3 “Assim, o monismo funda-se na tese da autossuficiência do ordenamento jurídico: o direito legitimase por si mesmo, independentemente de referências a valores morais ou políticos e dos e dos limites e insuficiências empíricas das instituições estatais. Como consequência, tem-se que as normas jurídicas são "recortadas" ou "descoladas" da realidade social na qual se inserem, constituindo uma "realidade" autônoma e altamente abstrata. Aqui a dogmática jurídica exerce papel fundamental. É o famigerado discurso hermético, supostamente neutro, pautado em ficções como a do "legislador racional", da completude do ordenamento e da segurança jurídica, que, em última instância, legitima o caráter intrinsecamente 'justo", 'universal” e autossuficiente do direito." (CARVALHO In WOLKMER, 2010, p.15.)
} 
demais? Qual seria a reparação integral (preconizada pela Lei) nestes casos em que o valor pecuniário nada representada para as vítimas do dano? Como seria a recomposição do meio ambiente, que é para estes um caso de sobrevivência? Ou ainda, como estabelecer a correta avaliação de danos ambientais, nas comunidades tradicionais, que em virtude das ações humanas que alterem este denominado modus vivendi e, a partir da premissa de sua peculiaridade e fragilidade únicas, bem como da dependência para a própria sobrevivência destes povos deste seu modo de ser e viver, avaliar e determinar a mais correta reparação?

É muito difícil que o Poder Judiciário responda com justiça a todas estas perguntas. Certamente estamos diante de um meio impróprio para a análise desta reparação, bem como das necessidades destes povos para que isso ocorra.

\section{O estado plurinacional e o pluralismo jurídico como uma melhor solução para os danos ambientais às comunidades tradicionais}

Claramente o Direito moderno brasileiro não possui condições de sanar os conflitos trazidos pela sociedade de risco no que diz respeito aos riscos e danos sofridos pelas denominadas comunidades tradicionais, devido à sua origem e concepção individualista 4 .

Somente um Direito baseado no multiculturalismo poderá "enxergar" os chamados direitos invisíveis dos povos, como direitos coletivos que se transformam em unidade de identidade.

É através deste pluralismo jurídico, que o direito passa a ter condições de vislumbrar o problema destas minorias, em face dos direitos dos demais, mas com maior legitimidade de ambos para fazê-los ${ }^{5}$.

Trata-se de uma nova visão ao Estado, através da inserção do plurinacionalismo e pluriculturalismo, o que segundo SANTAMARÍA não se trata de uma redundância, mas da materialização da inclusão de diver-

\footnotetext{
4 “Ora, a insuficiência do paradigma monista de tradição liberal e estatista enseja o entreabrir do horizonte pluralista, interdisciplinar e transcultural. É dentro dessa perspectiva direcionada para uma normatividade de fontes mais abertas, societárias e emergentes que se justifica (re)introduzir a discussão teórico-analítica e prático-metodológica acerca do fenômeno do pluralismo jurídico". (WOLKMER, 2010, p. 7.)

5 O Estado não detém o monopólio de produção de normas, de maneira que o direito não se resume ao direito estatal, mas envolve também um direito vivo, que surge no seio da própria sociedade, apresentando, às vezes, maior legitimidade do que os atos normativos emanados das instituições públicas.". (CARVALHO In WOLKMER, 2010, p. 16.)
} 
sas culturas (de lo distinto y de lo invisible) sem prejuízo da concepção de Estado concebida até então, muito pelo contrário, trata-se da inserção destas cultura a fim de "construir un buen vivir entre todos los habitantes de un Estado que garantiza la plena realización del sujeto colectivo como de los intereses individuales" (SANTAMARÍA, 2010, p. 11).

Sem o diálogo respeitoso das culturas envolvidas o descontentamento, e consequentemente, a injustiça serão inevitáveis.

Somente através do respeito mútuo, dos valores e das diferenças culturais, representados por si mesmos, é que se conceberão soluções satisfatórias aos conflitos.

Para SANTAMARÍA somente "un pluralismo jurídico pluricultural y plurinacional es el que permite el ejercicio pleno de los sistema jurídicos" (2010, p. 12).

A exemplo da viabilidade deste diálogo intercultural proposto pelo autor, temos na América Latina, algumas cortes e tribunais, dentre eles o Tribunal Constitucional Plurinacional da Bolívia, que como o próprio nome do tribunal sugere, trata-se de um órgão que promove soluções a conflitos que envolvem diferentes culturas na busca de uma harmonia (buen vivir) entre todos que constituem o Estado, garantindo a satisfação dos interesses e necessidades das minorias, sejam indígenas ou não, sem prejuízo dos anseios e interesses individuais (do homem contemporâneo).

No mesmo sentido a Corte Constitucional da Colômbia fora exemplo a toda América Latina, composta por pluralidade cultural sine qua non, ao reconhecer a importância do pluralismo como fonte de garantia de direitos a comunidades tradicionais, neste caso indígenas, passou a determinar o seguinte:

Los derechos fundamentales de las comunidades indígenas no deben confundirse con los derechos colectivos de otros grupos humanos. La comunidad indígena es un sujeto colectivo y no una simple sumatoria de sujetos individuales que comparten los mismos derechos o intereses difusos o colectivos. En el primer evento es indiscutible la titularidad de los derechos fundamentales, mientras que en el segundo los afectados 
pueden proceder a la defensa de sus derechos o intereses colectivos mediante el ejercicio de las acciones populares correspondientes. ${ }^{6}$

Nota-se claramente o reconhecimento do direito indígena como povo, na qualidade de identidade coletiva, e não individual, além do direito de ação a esta coletividade como meio de garantir o efetivo gozo destes direitos.

Deste modo, para uma reparação integral de danos ambientais aos povos tradicionais no Brasil, preliminarmente seria necessário aceitar sua cultura, seus valores e o seu "direito" para então dialogar permitindo que as escolhas e as necessidades de recomposição partam dos vitimados e não da sociedade poluente, sob pena de certa insatisfação, agressões mútuas e caos social.

Não se alcança este diálogo com um sistema jurídico monista, que não permite que os direitos tradicionais ou específicos destes povos sejam devidamente reconhecidos e aplicados, por isto a necessidade de um sistema multicultural ou pluralista, que coloque ambas culturas em um mesmo patamar e promova o diálogo entre estas objetivando a satisfação de ambos sem prejuízo de qualquer um destes, tal como já é uma realidade em alguns países da América Latina.

\section{As reparações de comunidades índigenas na Corte Interamerica- na de Direitos Humanos}

Dada as características atribuídas às comunidade tradicionais, especificamente as características que dizem respeitos a suas identidades e suas conexões culturais com o meio em que vivem, não restam dúvidas quanto a impossibilidade de reparação integral de danos ambientais através do sistemas monista, sendo indispensável o diálogo com estas comunidades através do pluralismo jurídico, objetivando a satisfação das necessidades de todos os envolvidos.

Tal como são os precedentes da Corte Interamericana de Direitos Humanos, que possui o entendimento consolidado quanto ao reconhecimento de comunidades indígenas (que não deixam de ser comunidades tradicionais) como sujeito coletivo, determinando em diversas deci-

6 CC Colômbia. ST-380 de 1993. M.P. Eduardo Cifuentes Muñoz, Sentencia T-769 de 2009. Magistrado Ponente Nilson Pinilla Pinilla. 
sões a necessidade de reparação de danos sofridos por estas comunidades na esfera dos direitos humanos, conforme preconizado pelo pacto de San Jose da Costa Rica.

0 entendimento hodierno da Corte Interamericana de Direitos Humanos identifica estas comunidade indígenas de forma diferenciada e dimensiona os tipos de reparações mais eficazes a estes que possuem suas necessidades e seu modo de ser e viver completamente diferente da maioria que compõe a sociedade:

El carácter de las violaciones como individuales o colectivas. Puede tratarse de un grupo afectado por violaciones similares pero que no constituye un colectivo definido, o un colectivo que sufre violación a sus derechos. La conceptualización jurídica del tipo de derecho violado, también le da un carácter individual o colectivo: por ejemplo, si se trata del derecho a la vida de diferentes personas o la violación de la capacidad de reproduccióndel grupo. Otro ejemplo es si se considera un derecho individual lesionado de muchas personas, o si se trata de derechos de carácter colectivo (como los casos de problemas de tierra en el caso Awas Tingni' ${ }^{7}$.

La prevención o garantías para otros colectivos. La reparación colectiva puede referirse a un grupo específico pero también, como extensión de la misma, a otros colectivos afectados por las mismas violaciones; en este sentido, las garantías de no repetición pueden considerarse como una forma de reparación colectiva.

El tipo de efectos. El impacto de una masacre puede valorarse como una suma de efectos individuales, pero también puede tener fuertes efectos colectivos de desestructuración del tejido social, pérdida de símbolos o de elementos de identidad comunitaria, como la relación con un territorio o la cultura (como en el caso Plan de Sánchez ${ }^{8}$ ).

La identidad colectiva: El tipo de identidad colectiva guarda relación con la violación y con el tipo de efectos, y tiene implicaciones para la reparación. Puede ser un colectivo con una identidad cultural diferencial (afro-

7 CORTE INTERAMERICANA DE DERECHOS HUMANOS. Caso de la Comunidad Mayagna (Sumo) Awas Tingni Vs Nicaragua. Sentencia de 31 de agosto de 2001. N. 79.

$8{ }^{8}$ CORTE INTERAMERICANA DE DERECHOS hUMANOS. Caso de la Masacre de Plan de Sánchez. Sentencia de 19 de noviembre de 2004. N. 116. 
descendiente o indígena, como Moiwana ${ }^{9}$ o Awas Tingni), con una definición territorial (comunitaria, como Pueblo Bello ${ }^{10}$ o Mapiripán ${ }^{11}$ ), cuya dimensión colectiva sea el régimen de coexistencia de vida (como la cárcel en el caso Panchito López ${ }^{12}$ ), una identidad ideológica (movimiento político, como la UP) o un elemento circunstancial ligado a una actividad profesional o social (La Cantuta ${ }^{13}$, ó 19 comerciantes $^{14}$ ). Cada una de estas situaciones, o la conjunción de varias de ellas en un caso, conlleva desafíos diferentes em términos de reparación colectiva.

Nota-se nos julgados trechos extraídos de julgados, que aquela Corte enfrenta as questões aqui suscitadas de forma a sopesar os direitos e características de todos os envolvidos, levando em consideração o ideal de "identidade coletiva" dos povos tradicionais, a relação destes com o meio em que vivem e os efeitos desta relação.

Nos julgados supra a Corte relacionou, tal como observa-se, o tipo de violação, os efeitos desta na qualidade de vida daquelas comunidades, para ao fim, e somente após a verificação destas particularidades, determinar as formas eficazes de reparação.

No mesmo sentido, o catedrático SANTAMARÍA, em entrevista na cidade de Bogotá, teceu algumas considerações acerca das particularidades que devem ser levadas em consideração na reparação de danos a estas comunidades:

La reparación cultural comprende los esfuerzos por reconstruir la armonía comunitaria, espiritual y social de los pueblos indígenas que es afectada por agresiones externas que interrumpen su orden natural.

9 CORTE INTERAMERICANA DE DERECHOS hUMANOS. Caso de la Comunidad Moiwana Vs. Surinam. Excepciones Preliminares, Fondo, Reparaciones y Costas. Sentencia 15 de junio de 2005. N. 124 .

10 CORTE INTERAMERICANA DE DERECHOS humANOS. Caso de la Masacre de Pueblo Bello Vs. Colombia. Fondo, Reparaciones y Costas. Sentencia de 31 de enero de 2006. N. 140.

11 CORTE INTERAMERICANA DE DERECHOS HUMANOS. Caso de la Masacre de Mapiripán Vs. Colombia. Fondo, Reparaciones y Costas. Sentencia de 15 de septiembre de 2005. N. 134.

12 CORTE INTERAMERICANA DE DERECHOS huMANOS. Caso "Instituto de Reeducación del Menor" Vs. Paraguay. Excepciones Preliminares,Fondo, Reparaciones y Costas. Sentencia de 2 de septiembre de 2004. N.ㅇ 112.

13 CORTE INTERAMERICANA DE DERECHOS huMANOS. Caso de La Cantuta Vs. Perú. Fondo, Reparaciones y Costas. Sentencia de 29 de noviembre de 2006. Serie C No. 162.

14 CORTE INTERAMERICANA DE DERECHOS HUMANOS. Caso del Comerciantes Vs. Colombia. Fondo, Reparaciones y Costas. Sentencia de 5 de julio de 2004. N. 109. 
La reparación de los pueblos indígenas es y debe ser diferente a la de las demás poblaciones, al menos por dos características que la fundamentan; la primera de ellas tiene que ver con el elemento cultural y la segunda con el elemento colectivo.

En este sentido, la noción de reparación cultural, considera que no basta con la indemnización a los pueblos sino que debe darse un esfuerzo de restablecimiento del orden, de cuyo contenido y posibilidades solo saben los mayores y autoridades tradicionales de cada pueblo indígena.

La perspectiva que propone no se ha hecho hasta el momento en ninguna experiencia de reparación nacional o internacional y que tampoco cree que se sepa cómo hacerlo, por ello, y dado que es una noción nueva, la reparación cultural debe construirse con y por los pueblos indígenas, quienes son, quienes deben pensar y re-pensar cómo debe ser la reparación para cada caso y para cada hecho que genere la obligación de repa$\operatorname{rar}^{15}$.

Além de uma visão diferenciada da utilizada tradicionalmente, o docente explica que a reparação deve ser completamente diferenciada, analisando as características espirituais e sociais dos povos que tem seu estado natural afetados por agressões externas ou da sociedade.

Adverte ainda que a reparação a estes povos deve restabelecer o estado anterior do dano, sempre analisando as particularidades caso a caso, afim de buscar uma reparação de cunho cultural, haja vista que o dano possui um caráter cultural, tratando-se de comunidades tradicionais.

Na mesma entrevista a Ginna Rodriguez, SANTAMARÍA, diz ter conhecimento de exemplos no Peru, onde indígenas ocupam cargo de autoridades e desempenham papéis preponderante na análise e na criação de meios de reparações de danos causados à comunidades indígenas daquele país.

\section{Conclusões finais}

15 SANTAMARÍA, Rosembert Ariza en entrevista realizada el 3 de diciembre de 2010 en Bogotá por Ginna Rodríguez. In RODRÍGUEZ, 2011. 
Completamente diversa do tradicional monismo jurídico, porém comprovadamente eficaz a aplicação do pluralismo jurídico a casos práticos se apresenta como mais eficaz para reparação de danos a comunidades tradicionais, dada as particularidades do vínculo existente entre os membros destas comunidades e o meio ambiente em que vivem.

Todavia, a aplicação deste pluralismo jurídico, deve pois, partir de uma análise minuciosa com vistas as particularidades do caso concreto, somados a participação ativa de membros das comunidades em diálogos interculturais.

Tanto pela jurisprudência das Cortes da América Latina, quanto pela doutrina e pelos exemplos de casos concretos, em países latino americanos, comprova a tendente e a necessária adoção de um Estado Plurinacional, onde um diálogo intercultural e um sistema jurídico pluralista busca soluções mais apropriadas para reparação integral de danos sofridos por comunidades tradicionais ou por outras minorias, principalmente diante da realidade social latino americana.

\section{Referências Bibliográficas}

BRASIL. Constituição (1988). Constituição da República Federativa do Brasil. Brasília, DF: Senado Federal, 1988.

. Lei n.․ 6.938 de 31 de agosto 1981. Dispõe sobre a Política Nacional do Meio Ambiente, seus fins e mecanismos de formulação e aplicação, e dá outras providências. Brasília, DF: Poder Executivo, 1981.

Decreto n. 6.040 de 07 de fevereiro de 2007. Institui a Política Nacional de Desenvolvimento Sustentável dos Povos e Comunidades Tradicionais. Brasília, DF: Poder Executivo, 2007.

CARVALHO, Lucas Borges de. Caminhos (e descaminhos) do pluralismo jurídico no Brasil. In WOLKMER, Antonio Carlos. (org.). Pluralismo jurídico: os novos caminhos da contemporaneidade. 1ํㅡㄹ. Ed. São Paulo: Saraiva, 2010.

CORTE CONSTITUCIONAL DE COLOMBIA. ST- 380 de 1993. M.P. Eduardo Cifuentes Muñoz, Sentencia T-769 de 2009. Magistrado Ponente Nilson Pinilla Pinilla.

CORTE INTERAMERICANA DE DERECHOS HUMANOS. Caso de La Cantuta Vs. Perú. Fondo, Reparaciones y Costas. Sentencia de 29 de noviembre de 2006. Serie C No. 162. 
Caso del Comerciantes Vs. Colombia. Fondo, Reparaciones y Costas. Sentencia de 5 de julio de 2004. N. 109.

Caso de la Comunidad Mayagna (Sumo) Awas Tingni Vs Nicaragua. Sentencia de 31 de agosto de 2001. N. 79 .

Caso de la Comunidad Moiwana Vs. Surinam. Excepciones Preliminares, Fondo, Reparaciones y Costas. Sentencia 15 de junio de 2005. N. 124.

Caso "Instituto de Reeducación del Menor" Vs. Paraguay. Excepciones Preliminares,Fondo, Reparaciones y Costas. Sentencia de 2 de septiembre de 2004. N.을 112 .

Caso de la Masacre de Mapiripán Vs. Colombia. Fondo, Reparaciones y Costas. Sentencia de 15 de septiembre de 2005. N. 134 .

Caso de la Masacre de Plan de Sánchez. Sentencia de 19 de noviembre de 2004. N.을 116 .

Caso de la Masacre de Pueblo Bello Vs. Colombia. Fondo, Reparaciones y Costas. Sentencia de 31 de enero de 2006. N. 140.

LEITE, José Rubens Morato. Dano ambiental na sociedade de risco. 1aㅡ. Ed. São Paulo: Saraiva, 2012.

; AYALA, Patryck de Araújo. Dano ambiental: do individual ao coletivo extrapatrimonial. Teoria e prática. 5a Ed. São Paulo: Editora Revista dos Tribunais, 2012.

LIPARI, Nicoló. La responsabilità dell'impresa per i danni all'ambiente e ai consumatori. Milano: Casa Editrice Giuffrè, 1978.

MARÉS, Carlos Frederico. Introdução ao direito socioambiental. In: LIMA, André. (org.). 0 Direito para o Brasil Socioambiental. 1르. Porto Alegre: Sergio Fabris, 2002.

Os direitos invisíveis. In: OLIVEIRA, Francisco de. (org.). Os sentidos da democracia: políticas do dissenso e hegemoniaglobal. 2ª Ed. Petrópolis: Vozes, 1999.

MILARÉ, Édis. Direito do ambiente: doutrina, jurisprudência, glossário. 4⿳ạ Ed. São Paulo: Editora Revista dos Tribunais, 2005.

RODRÍGUEZ. Ginna Marcela Rivera. Reparación a pueblos indígenas. Debates, aprendizajes y perspectivas. Bogotá: Universidad Nacional de Colombia, 2011. 
SANTAMARÍA, Rosembert Ariza. El pluralismo en el estado plurinacional, redundancia o pertinência. Revista Iusa, Universidad Santo Tomas. Bogotá, n.o 33, jul/dec. 2010.

SANTAMARÍA, Rosembert Ariza, En entrevista realizada el 3 de diciembre de 2010 en Bogotá. In RODRÍGUEZ. Ginna Marcela Rivera. Reparación a pueblos indígenas. Debates, aprendizajes y perspectivas. Bogotá: Universidad Nacional de Colombia, 2011.

SUPERIOR TRIBUNAL DE JUSTIÇA. Recurso especial n. n. 1.114.398/PR. Ministro Relator Luis Felipe Salomão. Julgamento em 18 de outubro de 2012.

WOLKMER, Antonio Carlos. (org.). Pluralismo jurídico: os novos caminhos da contemporaneidade. 1aㅡ Ed. São Paulo: Saraiva, 2010.

Recebido: $11 / 03 / 2015$

Received: 03/11/2015

Aprovado: 12/03/2015

Approved: 03/12/2015 